\title{
Induction of xylanase in thermophilic fungi Scytalidium thermophilum and Sporotrichum thermophile
}

\author{
Chetna Joshi and Sunil Kumar Khare* \\ Enzyme and Microbial Biochemistry Lab; Department of Chemistry; Indian Institute of Technology; Hauz Khas, \\ 110016; New Delhi - India
}

\begin{abstract}
Regulation of xylanase production in two thermophilic fungi Scytalidium thermophilum and Sporotrichum thermophile was investigated. The expression of xylanase was found to be inducible in both the cases. Various carbon sources were tested so as to identify the inducers. Soy flour and oat spelt xylan induced maximum level of xylanase in Scytalidium thermophilum and Sporotrichum thermophile respectively. Induction of xylanase in Scytalidium thermophilum led to simultaneous induction of cellulase. The zymography of enzyme preparations revealed that different carbon sources caused differential expression of multiple isoforms of xylanase in Scytalidium thermophilum, but same isoforms were expressed by Sporotrichum thermophile irrespective of the carbon source used.
\end{abstract}

Key words: Induction, isoforms, Xylanase, biobleaching

\section{INTRODUCTION}

Xylan is the principle type of hemicellulose. It is a heterogeneous polysaccharide consisting of a homopolymeric backbone of 1,4-linked- $\beta$-Dxylopyranose units and short chain branches including $O$-acetyl, $\alpha$-L-arabinofuranosyl, $\alpha$-Dglucuronyl residues (Whistler and Richards 1970). Xylan originating from different plant sources show differences in xylan branching and composition (Badhan et al. 2004). Cooperative action of multiple xylanases is required for xylan hydrolysis. These xylanases, therefore, have overlapping yet different specificities (Dekker and Richards 1976). The main activities involved in xylan hydrolysis are 1,4- $\beta$-xylanase and $\beta$ xylosidase (Polizeli et al. 2005). Presence of multiple forms of xylanases is reported in several microorganisms. Thermophilic fungi viz. Melanocarpus albomyces, Talaromyces byssochlamydoides (Hayashida et al. 1988), Humicola insolens (syn. Scytalidium thermophilum) (Dusterhoft et al. 1997), Chaetomium thermophile (Ganju et al. 1989), Myceliophthora sp (Badhan et al. 2004) are specially known to produce multiple xylanases.

Xylanases (in general all endoglycanases) act against large polysaccharides. Because of their size, polysaccharides cannot pass through the cell membrane to trigger the response for the synthesis of xylanases. However it is believed that low molecular-mass soluble catabolites are released from the action of low, constitutive amounts of hydrolases on xylan polymers. These catabolites enter the cell and signal to stimulate the synthesis of the respective enzymes (Sachslehner et al. 1998). Thus, the xylanases can be quite specifically induced.

Xylanases have attracted considerable research interest because of their potential application in the

\footnotetext{
*Author for correspondence: skhare@ rocketmail.com
} 
biobleaching of pulp (Kuhad and Singh 1993). Viikari et al. (1986) first reported that incorporation of xylanases for bleaching of kraft pulp decreases the use of chlorine for bleaching thereby reducing the hazardous effluent of pulp and paper industry. Pulping and bleaching are performed at high temperatures. Hence, the paper industries need xylanases that are thermostable (Srinivasan and Rele 1999). Xylanases are mostly contaminated with cellulases, which destroy the structure of cellulose and diminish pulp quality. For this reason pulp and paper industries require cellulase-free xylanases. If xylanases and cellulases can be induced differentially it may lead a simple approach for cellulase free xylanase production.

Keeping all these facts in mind xylanase production in two different thermophilic fungi Scytalidium thermophilum and Sporotrichum thermophile was studied. The inducing or repressing effects of various easily metabolizable monosaccharides, polysaccharides and lignocelluloses on xylanase production were evaluated and multiplicity in xylanases was identified. The production of cellulase was examined simultaneously.

\section{MATERIALS AND METHODS}

\section{Materials}

The culture media ingredients were procured from Hi Media Laboratories (Mumbai, India). Xylan (from oat spelt) was purchased from Sigma Chemicals (St. Louis, USA). All other chemicals used were of analytical grade. CM cellulose was purchased from CDH (P) Ltd. (Delhi, India).

\section{Culture and growth medium}

Scytalidium thermophilum was provided by Dr. Lata, Division of Microbiology, IARI, New Delhi, India; whereas Sporotrichum thermophilum was a kind gift from Prof. T. Satyanarayana, Department of Microbiology, University of Delhi South Campus, New Delhi, India.

Scytalidium thermophilum and Sporotrichum thermophile were maintained on PDA and Emerson's YpSs agar respectively. For Scytalidium thermophilum the $\mathrm{pH}$ of the PDA media was adjusted to 9.0. The composition of YpSs agar was $(\mathrm{g} / \mathrm{l})$, soluble starch 15.0; yeast extract 4.0; $\quad \mathrm{KH}_{2} \mathrm{PO}_{4}, \quad 2.0 ; \quad \mathrm{K}_{2} \mathrm{HPO}_{4}, \quad 1.5$; $\mathrm{MgSO}_{4} \cdot 7 \mathrm{H}_{2} \mathrm{O}, 0.5$, adjusted to $\mathrm{pH} 7.0$. These were maintained at $4{ }^{\circ} \mathrm{C}$ and sub-cultured at monthly intervals.

Inoculum was prepared by seeding two pieces of approximately $1.0 \mathrm{~cm}^{2}$ of mycelial mat from the actively growing part of stock cultures into $500 \mathrm{ml}$ Erlenmeyer flasks containing $100 \mathrm{ml}$ glucose/urea basal medium of following composition $(\mathrm{g} / \mathrm{l})$ : glucose, 10; yeast extract, $10 ; \mathrm{KH}_{2} \mathrm{PO}_{4}, 6.0$; $\mathrm{K}_{2} \mathrm{HPO}_{4}, 0.4 ; \mathrm{MgSO}_{4} \cdot 7 \mathrm{H}_{2} \mathrm{O}, 0.5$; urea, 0.5. For Scytalidium thermophilum $\mathrm{pH}$ was kept at 9.0 while for Sporotrichum thermophile $\mathrm{pH}$ was adjusted to 7.0. Inoculums were grown at $45{ }^{\circ} \mathrm{C}$ for $72 \mathrm{~h}$. Sporotrichum thermophile was grown with shaking at $150 \mathrm{rpm}$ whereas for Scytalidium thermophilum static conditions were maintained.

\section{Induction and repression}

The induction of xylanase in Scytalidium thermophilum and Sporotrichum thermophile was studied by growing cultures in basal medium (discussed above) wherein glucose is replaced by $1 \%(\mathrm{w} / \mathrm{v})$ monosaccharides (fructose, galactose, and xylose) or polysaccharides (xylan, CMcellulose, avicel) or lignocelluloses (wheat straw, rice straw) or soy flour as carbon source. The synergistic effect of different substrates $(1 \%, \mathrm{w} / \mathrm{v}$ or $\mathrm{v} / \mathrm{v})$ glucose, fructose, sucrose, cellobiose, sorbitol, mannitol, glycerol or ethanol in combination with inducer soy flour $(1 \%, \mathrm{w} / \mathrm{v})$ in case of Scytalidium thermophilum and xylan (1\%, $\mathrm{w} / \mathrm{v}$ ) in Sporotrichum thermophile was studied in basal medium containing all the components except glucose. The $500 \mathrm{ml}$ Erlenmeyer flasks containing $100 \mathrm{ml}$ media were seeded with $4 \%$, $72 \mathrm{~h}$ grown inoculum of Scytalidium thermophilum and Sporotrichum thermophile and incubated at $45^{\circ} \mathrm{C}$. The samples were withdrawn at $24 \mathrm{~h}$ interval, centrifuged at $10,000 \mathrm{rpm}$ for 10 min (Sigma 2-16 K, Germany) and supernatant was assayed for xylanase and cellulase activity.

\section{Enzyme assays}

Xylanase activity was determined using oat-spelt xylan as substrate (Bailey et al. 1992). The resultant reducing sugars were estimated by dinitrosalicylic acid (DNSA) method (Miller 1959).

Cellulase (Endo- $\beta-1,4-\mathrm{D}$-glucanase) activity was determined in accordance with International Union of Pure and Applied Chemistry (Ghosh 1987). 
One unit of enzyme activity is defined as the amount of enzyme required to produce $1 \mu \mathrm{mol}$ reducing sugar (measured as xylose/glucose) per minute under assay conditions.

\section{Poly-acrylamide gel electrophoresis and} zymography

The zymography for the xylanase activity was carried out according to the method of Ratanakhanokchai et al. (1999). The culture was centrifuged $(10,000 \mathrm{xg})$ for $10 \mathrm{~min}$ and supernatant was taken for PAGE analysis. Culture supernatant containing $20 \mu \mathrm{g}$ protein was subjected to SDSPAGE gel containing $0.1 \%$ xylan. The electrophoresis was done according to the method of Laemmli (1970). Electrophoresed gel was soaked in $25 \%(\mathrm{v} / \mathrm{v})$ isopropanol with gentle shaking to remove the SDS and renature the proteins in the gel. It was then washed four times for $30 \mathrm{~min}$ at $4{ }^{\circ} \mathrm{C}$ in sodium phosphate buffer $(0.1$ $\mathrm{M}, \mathrm{pH}$ 6.0). After further incubation at $50{ }^{\circ} \mathrm{C}$ for $60 \mathrm{~min}$ in the same buffer, the gel was soaked in $0.1 \%$ Congo red solution for $30 \mathrm{~min}$ at room temperature and washed with $1 \mathrm{M} \mathrm{NaCl}$ until excess dye was removed from the active band. The gel was submerged in $0.5 \%$ acetic acid, the background turned dark blue and the activity bands were observed as clear colourless areas.

All the experiments were performed in triplicate and the variation was within $\pm 4 \%$.

\section{RESULTS}

Production of xylanase from Scytalidium thermophilum and Sporotrichum thermophile

Two known xylanase producers Scytalidium thermophilum and Sporotrichum thermophile were used in this study. These produced maximum 0.24 $\mathrm{U} / \mathrm{ml}$ and $0.12 \mathrm{U} / \mathrm{ml}$ xylanase respectively in glucose basal media (Table 1).

Effect of various easily metabolizable monosaccharides, polysaccharides, lignocelluloses and protein rich soy flour was checked on xylanase production.

Xylanase activity was the lowest when cultures were grown in presence of $1 \%(\mathrm{w} / \mathrm{v})$ easily metabolizable monosaccharides i.e. glucose, fructose, galactose and xylose in both the cases. Lignocelluloses moderately enhanced xylanase production in Sporotrichum thermophile whereas xylan induced it maximally. In Scytalidium thermophilum soy flour and wheat straw enhanced xylanase production by $98 \%$ while it is completely inhibited by xylose.

Scytalidium thermophilum produced maximum xylanase on $12^{\text {th }}$ day of fermentation in presence of soy flour $(14.4 \mathrm{U} / \mathrm{ml})$ whereas Sporotrichum thermophile produced it maximum $(1.07 \mathrm{U} / \mathrm{ml})$ on $4^{\text {th }}$ day of fermentation in presence of xylan. Hence in subsequent studies soy flour and xylan were added in place of glucose in to the basal media as xylanase inducer for Scytalidium thermophilum and Sporotrichum thermophile respectively.

Table 1 - Effect of various carbon sources on xylanase production by Scytalidium thermophilum and Sporotrichum thermophile.

\begin{tabular}{ccc}
\hline & $\begin{array}{c}\text { Sporotrichum thermophile } \\
\text { Xylanase }(\mathbf{U} / \mathbf{m l})\end{array}$ & $\begin{array}{c}\text { Scytalidium thermophilum } \\
\text { Xylanase (U/ml) }\end{array}$ \\
\hline Monosaccharides & 0.12 & 0.24 \\
Glucose & 0.19 & 0.11 \\
Fructose & 0.12 & 0.10 \\
Galactose & 0.13 & $\mathrm{ND}$ \\
Xylose & & \\
Polysaccharides & 1.09 & 0.88 \\
CM-Cellulose & 0.31 & 0.57 \\
Avicel & 4.23 & 0.95 \\
Xylan & & \\
Lignocellulose & 1.07 & 12.76 \\
Wheat Straw & 0.58 & 0.77 \\
Rice Straw & 0.35 & 14.44 \\
Soy Flour & &
\end{tabular}


Regulation of xylanase and cellulase in presence of inducer

The production of xylanase in Scytalidium thermophilum was repressed when glucose and fructose were co-supplemented to soy flour medium (Fig. 1).

Sorbitol, mannitol, glycerol and ethanol also negatively influenced the xylanase production in Scytalidium thermophilum. Whereas addition of $1 \%(\mathrm{w} / \mathrm{v})$ sucrose and cellobiose resulted in $22 \%$ and $35 \%$ increase in xylanase activity respectively. Effect on cellulase level was checked simultaneously. Sucrose and cellobiose which induced xylanase also enhanced cellulase production (18\% and $41 \%$ respectively).

In Sporotrichum thermophile xylan was taken as inducer, over which addition of $1 \%(\mathrm{v} / \mathrm{v})$ glycerol and ethanol further increased the xylanase production by $28 \%$ and $37 \%$ respectively (Fig. 2). Glucose, fructose, sucrose, cellobiose and sorbitol showed negative effect on xylanase production. The advantage of Sporotrichum thermophile was apparent here, as its xylanase was found to be free of cellulase.

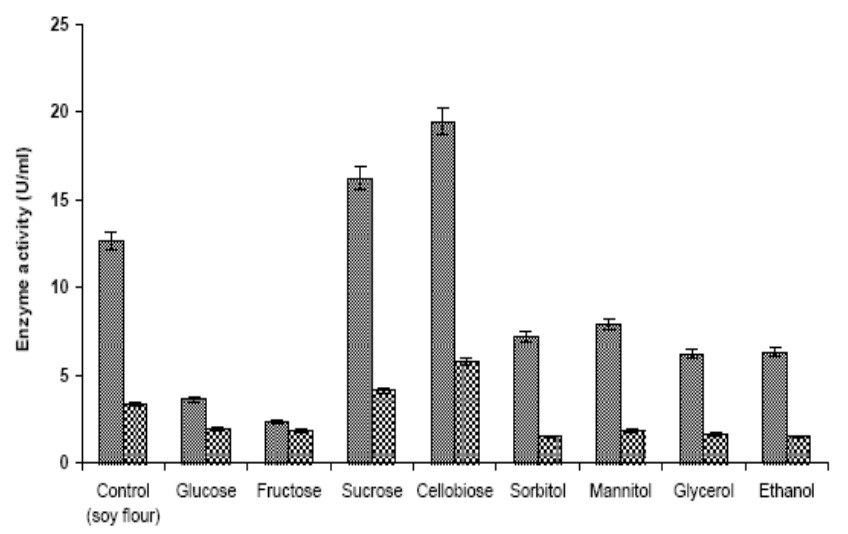

Figure 1- Effect of different substrates on xylanase and cellulase production by Scytalidium thermophilum in presence of inducer soy flour. Control consisted of basal media (except glucose) and soy flour (1\%,w/v). $\quad$; xylanase and $\mathbf{Q}$ cellulase.

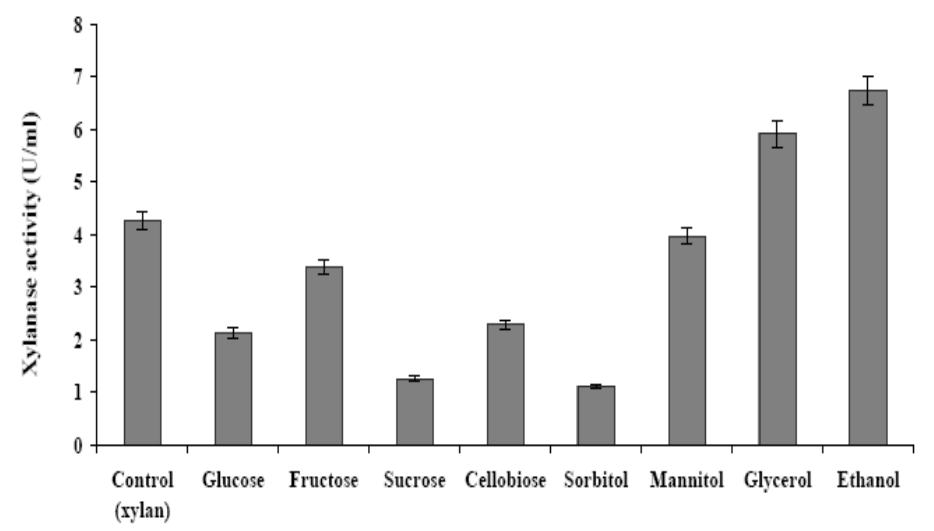

Figure 2 - Effect of different substrates on xylanase production by Sporotrichum thermophile in presence of inducer oat spelt xylan. Control consisted of basal media (except glucose) and oat spelt xylan $(1 \%, \mathrm{w} / \mathrm{v})$. 
Production profile of xylanase enzyme by Scytalidium thermophilum and Sporotrichum thermophile

Time course of xylanase production in Scytalidium thermophilum and Sporotrichum thermophile was investigated in presence of the substrate along with inducer. Production profile revealed that in the culture of Scytalidium thermophilum (containing soy flour only) highest level of xylanase $(12 \mathrm{U} / \mathrm{ml})$ was attained after 12 days which was followed by steady decline. On the $10^{\text {th }}$ day of fermentation maximum xylanase was released in the medium containing sucrose $(16.24 \mathrm{U} / \mathrm{ml})$ and cellobiose $(19.5 \mathrm{U} / \mathrm{ml})$ ) along with soy flour, Addition of glucose repressed xylanase production.

In case of Sporotrichum thermophile, addition of ethanol and glycerol enhanced the xylanase production by $37 \%$ and $28 \%$ respectively. Maximum production was achieved on $6^{\text {th }}$ and $7^{\text {th }}$ day of cultivation respectively. Glucose exhibited repressive effect with low level of production.
Expression of xylanase isoforms in Scytalidium thermophilum and Sporotrichum thermophile Xylanase is reported to exist in many isoforms (Badhan et al. 2004; Dusterhoft et al. 1997).The xylanase isoforms were checked by SDS-PAGE and activity staining. The results in Figure 3 revealed that in case of Scytalidium thermophilum the expression of different xylanase isoforms was dependent on the carbon source. Three xylanase isoforms (Ia, Ib and Ic) were detected in the presence of soy flour (lane1). Only one isoform Ic was obtained when sucrose or glucose was added to the inducer (soy flour) (Lane 2 and 3). The expression of more then one isoforms was detected in case of complex lignocelluloses (Lane 4 and 5). Xylan and cellobiose also led to expression of only one isoform (Lane 6 and 7). Wheat straw and rice straw induced two isoforms (lane 4 and 5). In Sporotrichum thermophile different carbohydrates promoted the expression of the same multiple isoforms ( $\mathrm{Ia}, \mathrm{Ib}$ ) of xylanase as evident from the similar band patterns in zymogram.

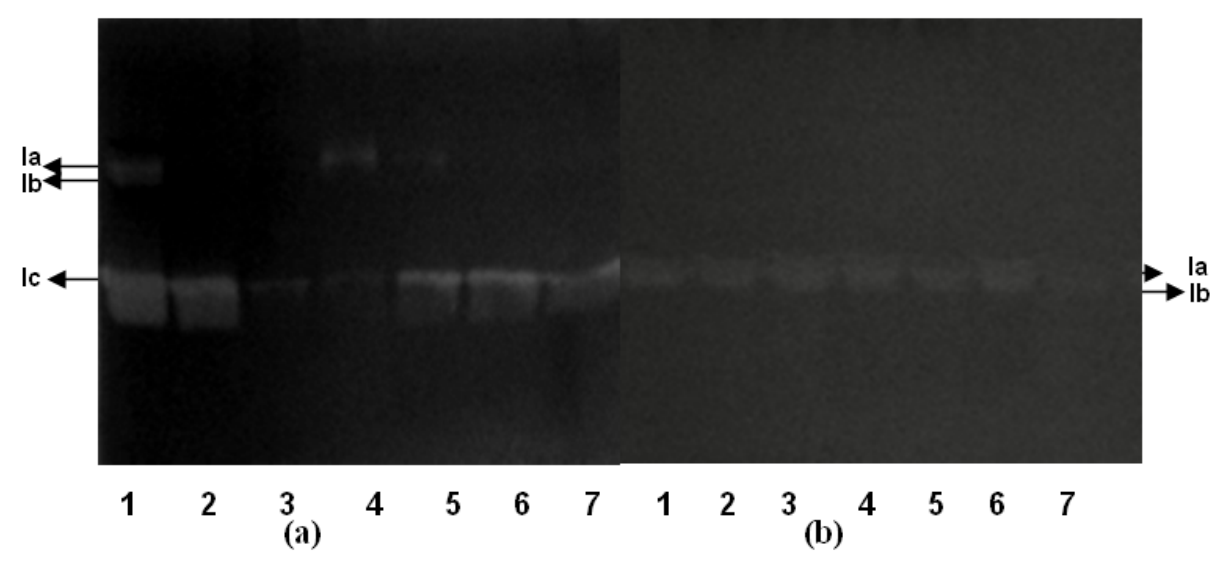

Figure 3- Zymography of extracellular proteins from Scytalidium thermophilum and Sporotrichum thermophile. a) Scytalidium thermophilum. Lanes from left to right: (1) soy flour (2) soy flour and sucrose (3) soy flour and glucose (4) wheat straw (5) rice straw (6) xylan (7) cellobiose. b) Sporotrichum thermophile. (1) xylan (2) xylan and glycerol (3) Xylan and glucose (4) xylan and ethanol (5) Wheat straw (6) Rice straw (7) Soy flour. $20 \mu \mathrm{g}$ of protein was applied in each well for the detection of xylanase activity.

\section{DISCUSSION}

Scytalidium thermophilum a deuteromycete, is predominant fungal strain in mushroom composting soils. Based on the results of this study it observed that formation of xylanase and endoglucanase are inducible in both Scytalidium thermophilum and in Sporotrichum thermophile. This is in agreement with several other fungi that have been investigated with respect to the 
regulation of xylanase biosynthesis (Biely 1993; Sachslehner et al. 1993).

In the present study it was observed that low level of xylanase is produced in presence of easily metabolizable carbon sources such as glucose, fructose, galactose and xylose. Maximum inducibility of xylanase and cellulase in Scytalidium thermophilum was achieved by soy flour and wheat straw, which can be ascribed to the heterogeneous nature and structural complexity of the substrate (Morag et al. 1990). On the contrary rice straw did not support xylanase production. Rice straw has a lower hemicellulose content which is masked by high silica content, thereby, decreasing the accessibility of xylan (Jain 1995). This might be a reason for low xylanase production in rice straw $(1 \%, w / v)$ containing media. Cellobiose induced the synthesis of both xylanase and cellulase. Similar inducing effect was also observed in A. terreus and can be explained by a structural similarity between cellobiose and xylobiose (Hrmova et al. 1989). In Scytalidium thermophilum synthesis of xylanase and cellulase occurred concomitantly i.e. there is co-regulation of xylanase and cellulase synthesis and synthesis of only one of these enzyme activities could not be specifically provoked by selecting corresponding substrate. When glucose was added to the inducer medium (soy flour in basal media for Scytalidium thermophilum and xylan in basal medium for Sporotrichum thermophile) xylanase production started only after exhaustion of glucose. In Scytalidium thermophilum it reached to the significant level after 16 days. This is similar to the results obtained by Sachslehner (1998) when significant mannanase formation commenced only when glucose was exhausted from the medium.

In case of Sporotrichum thermophile xylan induced maximum xylanase. Addition of glycerol and ethanol to the xylan containing basal medium enhanced the xylanase production to appreciable amounts. Induction by glycerol has also been reported in Thermomyces lanuginosus by Hoq et al. (1994). Ethanol implicated to be a physiological inducer for the expression of cellulase operon (Kaur et al. 2006). Surprisingly it enhanced xylanase production in Sporotrichum thermophile. Sporotrichum thermophile did not produce cellulase.

In case of Scytalidium thermophilum, the zymogram of enzyme preparations showed three xylanase isoforms in presence of inducer soy flour. Expression reduced to only one isoform when glucose was added to the inducer soy flour. Similar observations on differential expression of multiple xylanase isoforms have been reported in Myceliophthora sp. (Badhan et al. 2004). This confirms the differential expression of multiple xylanase isoforms in Scytalidium thermophilum dictated by carbon sources. However in case of Sporotrichum thermophile the same multiple isoforms of xylanase (Ia and Ib) are expressed irrespective of the type of carbon source.

The concomitant production of xylanase and cellulase cannot be regulated in case of Scytalidium thermophilum. But in case of Sporotrichum thermophile xylanase was free of cellulase. Xylanases free of cellulases are safe for the structure of cellulose and biobleaching by this enzymatic preparation can produce high quality pulp. Thus xylanase produced from Sporotrichum thermophile can find wide applications in the pulp and paper industry.

\section{CONCLUSIONS}

Based on the results of this study it was observed that formation of xylanase and endoglucanase are inducible in both Scytalidium thermophilum and in Sporotrichum thermophile. The concomitant production of xylanase and cellulase cannot be regulated in case of Scytalidium thermophilum. But in case of Sporotrichum thermophile xylanase was free of cellulase. Xylanases free of cellulases are safe for the structure of cellulose and biobleaching by this enzymatic preparation can produce high quality pulp. Thus xylanase produced from Sporotrichum thermophile can find wide applications in the pulp and paper industry.

\section{ACKNOWLEDGEMENT}

Scytalidium thermophilum was kindly provided by Dr Lata, Division of Microbiology, IARI, New Delhi, India. Sporotrichum thermophile was a generous gift by Prof. T. Satyanarayana, Department of Microbiology, South Campus, University of Delhi. New Delhi, India. Chetna Joshi is grateful to University Grant Commission, New Delhi for the Senior Research fellowship. 


\section{REFERENCES}

Bailey MJ, Biely P, Poutanen K. Interlaboratory testing of methods for assay of xylanase activity. J Biotech. 1992; 23:257-270.

Badhan AK, Chadha BS, Sonia KG, Sainia HS, Bhatb MK. Functionally diverse multiple xylanases of thermophilic fungus Myceliophthora sp. IMI 387099. Enzyme Microbial Technol. 2004; 35: 460-466.

Biely P. Biochemical aspects of the production of microbial hemicellulases. In: Coughlan MP, Hazlewood GP, editors. Hemicellulose and hemicellulases. London: Portland Press; 1993. p. 2951.

Dekker RF, Richards GN. Hemicellulases: their occurrence, purification, properties and mode of action. Adv Carbohydr Chem Biochem. 1976; 32: 277-352.

Dusterhoft EM, Linseen VAJM, Voragen AGJ, Beldman G. Purification, characterization and properties of two xylanases from Humicola insolens. Enzyme Microbial Technol. 1997; 20: 437-445.

Ganju RK, Vithayathil PJ, Murthy SK. Purification and characterization of two xylanase from Chaetomium thermophile var. coprophile. Can J Microbiol. 1989; 35: 836-842.

Ghosh TK. Measurement of cellulase activities. Pure Appl Chem. 1987; 59: 257-268.

Hayashida SK, Ohta MK, Wood AGJ. Xylanases of Talaromyces bussochlamydoides. In: Kellogg $\mathrm{T}$, Partridge ST, editors. Methods in Enzymology. London: Academic Press; 1988. p. 675-678.

Hoq MM, Hempel C, Deckwer WD. Cellulase-free xylanase by Thermomyces lanuginosus RT9: Effect of agitation, aeration, and medium components on production. J Biotech. 1994; 37: 49-58.

Hrmova M, Biely P, Vranskd M. Cellulose and xylandegrading enzymes of Aspergillus terreus and Aspergillus niger. Enzyme Microbial Technol. 1989; 11: 610-616.

Jain A. Production of xylanase by thermophilic Melanocarpus albomyces IIS-68. Process Biochem. 1995; 30: 705-709.
Kaur J, Chadha BS, Saini HS. Regulation of cellulase production in two thermophilic fungi Melanocarpus sp. MTCC 3922 and Scytalidium thermophilum MTCC 4520. Enzyme Microbial Technol. 2006; 38: 931-936.

Kuhad RC, Singh A. Lignocellulosic biotechnology: current and future prospects. Crit Rev Biotechnol. 1993; 13: 151-172.

Laemmli UK. Cleavage of structural proteins during the assembly of the head of bacteriophage T4, Nature. 1970; 227: 680-685.

Miller GL. Use of dinitrosalicylic acid reagent for determination of reducing sugars. Anal Chem. 1959; 31: 426-428.

Morag E, Bayer EA, Lamed R. Relationship of cellulosomal and noncellulosomal xylanases of Clostridium thermophilum to cellulose degrading enzymes. J Bacteriol. 1990; 172: 6098-6105.

Polizeli MLTM, Rizzatti ACS, Monti R, Terenzi HF, Jorge JA, Amorim, DS. Xylanases from fungi: properties and industrial applications. Appl Microbiol Biotechnol. 2005; 67: 577-591.

Ratanakhanokchai K, Kyu KL, Tanticharoen M. Purification and properties of a xylan-binding endoxylanase from alkaliphilic Bacillus sp. strain K1. Appl Environ Microbiol. 1999; 65: 694-697.

Sachslehner A, Nidetzky B, Kulbe KD, Haltric D. Induction of mannanase, xylanase, and endoglucanase activities in Sclerotium rolfsii. Appl Environ Microbiol. 1998; 64, 594-600.

Srinivasan MC, Rele MV. Microbial xylanases for paper industry. Curr Sci.1999; 77: 137-142.

Viikari L, Ranua M, Kantelinen A, Sundquist J, Linko M. Bleaching with enzymes. In: $3^{\text {rd }}$ International conference on biotechnology in the pulp and paper industry: Proceedings: 1986 June; Stockholm, Sweden. p. 67-69.

Whistler RL, Richards EL, Hemicellulose. In: Pigman W, Horton D, editors. The carbohydrate, New York: Academic Press; 1970. p. 447-469.

Received: March 19, 2011; Revised: July 03, 2011; Accepted: September 25, 2011. 


$$
\begin{gathered}
\text { PÁGINA } \\
\text { EM } \\
\text { BRANCO }
\end{gathered}
$$

